\title{
Spatio-temporal analysis of the impact of climate, cropping intensity and means of irrigation: an assessment on rice yield determinants in Bangladesh
} CrossMark

Iffat Ara ${ }^{1,2^{*}}$, Megan Lewis ${ }^{1}$ and Bertram Ostendorf ${ }^{1}$

\begin{abstract}
Background: Rice (Oryza sativa) is the most important staple food for almost half of the global population. Improvement of rice yield is of global concern and is influenced by a wide variety of regional factors including climate and agricultural management. This research addresses the need to understand the relative influence of these factors and develop geographically explicit determinants of rice yield across Bangladesh. The specific objectives of this study were (a) to assess spatial and temporal variation in rice yield, cropping intensity and means of irrigation, and (b) to evaluate the relative importance of spatio-temporal change in climate, cropping intensity and means of irrigation on rice yield. A database on rice yield, management practices (cropping intensity and means of irrigation) and climate was collected from the Bangladesh Bureau of Statistics and Bangladesh Meteorological Department, respectively, for the years of 1981-2010. Linear mixed models were used to assess the influence of different determinants on rice yield.
\end{abstract}

Results: The results indicate that irrigation, particularly groundwater irrigation, had a stronger influence on rice yield than climatic conditions and cropping intensity in Bangladesh during the study period. Temperature and rainfall showed negative impacts on yield. Rice yield also declined when cropping intensity increased.

Conclusions: Both climate and groundwater extraction need to be considered in future policy development. However, the current extraction rate of groundwater may not be sustainable in the future to increase rice yield. The study concludes that spatio-temporal differences in observed yield allow interpretation of potential determinants that are important for food policy development in Bangladesh.

Keywords: Food security, Climate change, Regional management, Irrigation, Intensification, Agriculture, Pumping, Linear mixed model

\section{Background}

The effective management of natural resources and agricultural production depends on solid, geographically explicit evidence [1]. In order to devise regional development plans and successful agricultural policies, it is important to understand which factors influence the complex agriculture system in a region [2]. The effects of climate variability and natural resources management

\footnotetext{
*Correspondence: iffatara.ju@gmail.com

1 School of Biological Sciences, The University of Adelaide, Adelaide 5005, Australia

Full list of author information is available at the end of the article
}

are the key determinants for production in many agricultural systems [3-5]. Resources management, mainly land and water management, seem to be the most influential determinants in many countries [6-9]. It is acknowledged that variation in climate and agricultural management practices influences crop yield [10]. However, there is little systematic analysis on which factors determine regional agricultural production. In particular, little is known about the spatially variable determinants of crop yield and production for rice in South Asia, including Bangladesh. 
Rice is the most important staple food for almost half of the global population [11]. Around $90 \%$ of the world's rice grows and is consumed in Asian countries, and of them, Bangladesh is the fourth-highest rice-producing country in the world [12]. Rice is vital for Bangladesh as 150 million people depend on it for $70 \%$ of direct calorie intake [13]. Rice occupies $77 \%$ of the arable land in Bangladesh [14], and the country contributed nearly $9 \%$ of the world's total rice in 2010 [12]. Understanding of factors that influence rice yield in Bangladesh is critical because food security primarily depends on food availability through rice production.

There is substantial uncertainty about how climate and other variables affect rice yield and production in Bangladesh $[15,16]$. Simulation models, such as Crop Environment Resource Synthesis (CERES) and Decision Support System for Agro-technology Transfer (DSSAT), generally predict a reduction of yield under future climate scenarios [17-19]. The response is dependent on rice ecotype, with rain-fed types showing negative temperature responses and mixed results for the irrigated variety Boro $[17,20,21]$. At the broad scale, production will likely be reduced by an expected future increase in flooding events and potentially be increased by $\mathrm{CO}_{2}$ fertilization [19]. In contrast, empirical analyses of government statistics relating rice yield historic records to climatic variables show positive past response of yield to higher temperatures for Aus and Aman varieties [22, 23]. However, the effect of rainfall in these empirical models is highly variable and differs significantly among regions and eco-types [23].

Bangladesh has made remarkable achievements in rice production. Water management and cropping intensity have substantially influenced rice production in the country $[24,25]$, and these may possibly impact rice production in future [26-28]. During the 1990s, rain-fed agriculture shifted to irrigation-based agriculture utilizing both surface and groundwater. Presently, nearly 8.52 million hectares (64 \% of the total land area) are arable, and of them, 6.15 million hectares are cultivated under different types of irrigation (power pumps, tube wells, canals and other forms) [29]. Bangladesh is now one of the highest users of groundwater irrigation in the world [30], delivered through power pumps and tube wells [31]. At present, groundwater irrigation covers $77 \%$ of the total irrigated area [32]. Furthermore, there is potential to intensify agriculture by increasing the number of annual crop harvest cycles using groundwater and surface water irrigation [27, 31]. However, how the area under different types of irrigation and the cropping patterns in different districts of Bangladesh has changed rice production has not been analysed yet, although it is known that water requirement for rice production varies regionally [25]. In addition, the combined effects of climate change, irrigation, and cropping intensity on rice yield have not been assessed, which has implications for food policy in the country [33, 34]. It is crucial to evaluate the factors which have influenced yield in the past in order to predict possible future trends in rice production for effective food policy development.

In the present study, we analyse the spatial and temporal variation in rice yield in Bangladesh for 30 years as influenced by the three important potential determinants climate, cropping intensity and means of irrigation. The specific objectives of the study are (a) to assess spatial and temporal variation in rice yield, cropping intensity and irrigation types, and (b) to evaluate the relative importance of spatio-temporal change in climate, cropping intensity and means of irrigation on rice yield.

\section{Methods}

The geographic extent for the analysis is the entire country of Bangladesh at the level of 23 greater districts (Fig. 1). Annual data of rice production, management (cropping intensity and irrigation) and climatic conditions were compiled for these districts for the period 1981-2010. The key sources of data are the Bangladesh Bureau of Statistics (BBS) and the Bangladesh Meteorological Department (BMD).

\section{Rice production and yield}

Bangladesh produces three eco-types of rice: Aus, Aman and Boro. These three eco-types are grown in different seasons [35] with varying needs for irrigation. Aus varieties are grown during the Kharif-I season (typically March to August) and potentially require irrigation water around planting time [27]. Aman varieties are grown during the Kharif-II season (typically June to November), and are predominantly rain-fed, although benefit from supplementary irrigation in case of shortage of water [36]. Boro rice is entirely dependent on irrigation and is grown during the Rabi season from December to March. Rice production and area under rice cultivation data for all eco-types for the 23 greater districts were sourced from Agricultural Statistical Year Books of Bangladesh, published by BBS from 1981 to 2010. Annual average rice yield (in $t / h a$ ) used in the models was then calculated as the sum of rice production for all eco-types divided by the sum of total area planted to rice in a year. It needs to be noted that the total cultivation area is generally larger than the geographic extent used for cropping (net cropped area) because different eco-types can be grown in sequence within a year, allowing multiple annual harvests. This is indicated by cropping intensity, as described below. 


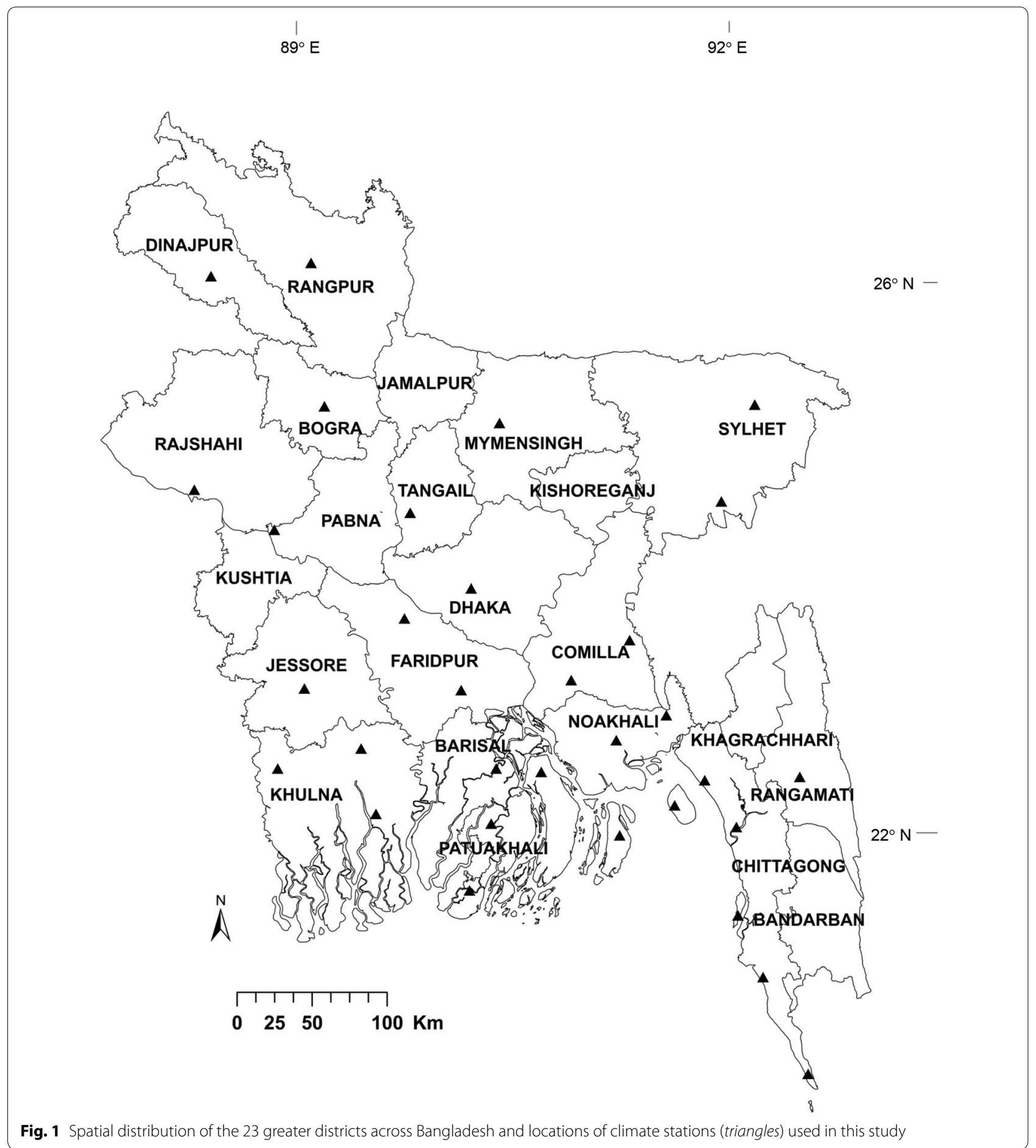

\section{Cropping intensity}

Cropping intensity indicates the number of harvest cycles that are undertaken per year in a given area. For each district and year, data are collected by the BBS about the geographic extent under single, double or triple cropping regimes. The sum of areas under these different management regimes is net cropped area. Unfortunately, this statistic is only available aggregated for all types of crops and not for rice, but it is possible to assume that the data are representative for rice, because rice is the predominant crop in Bangladesh. Total cultivation area is estimated a weighted sum of single, double and triple 
cropping areas with weights of 1,2 and 3 , respectively. Cropping intensity is then calculated as a percentage of total cultivation area divided by net cropped area.

\section{Irrigation}

Area under irrigation for each year was sourced for four categories: (1) power pumps/low lift pumps (methods used to lift surface water); (2) deep, shallow and hand tube wells (methods which pump groundwater); (3) canals (surface water irrigation using gravity); and (4) other methods (indigenous methods of surface water irrigation). These data were sourced from reports of Agricultural Statistical Year Books of Bangladesh, published by the Bangladesh Bureau of Statistics (BBS).

\section{Climate}

Station-based climate data were obtained from the Bangladesh Meteorological Department [37]. We used Kriging (implemented in ArcGIS) to interpolate the climate data spatially on a monthly basis for the years 1981-2010. Monthly rainfall and monthly mean minimum and maximum temperature were sourced from 31 weather stations (Fig. 1) based on data availability for both rainfall and temperature during the study period. The monthly average temperature was estimated as the average of minima and maxima for the interpolation procedure. Spatially and temporally averaged annual rainfall $(\mathrm{mm})$ and mean annual temperature $\left({ }^{\circ} \mathrm{C}\right)$ were then extracted for each district and year during 1981-2010.

\section{Analysis}

Summary statistics of the data are presented in Table 1, illustrating the broad climatic characteristics and management practices (cropping intensity and means of irrigation as a percentage of area per total district land area) for the time period 1981-2010 at greater district level. However, these descriptive statistics do not provide any evidence of the influence of geographic variations in climate and management practices on rice yield. To build

Table 1 Summary statistics for all variables used in the models (mean, standard deviation, minimum and maximum)

\begin{tabular}{|c|c|c|c|c|}
\hline Statistics & Mean & SD & Min & Max \\
\hline Rice yield (t/ha) (Y) & 1.96 & 0.53 & 0.85 & 3.25 \\
\hline Average temperature $\left({ }^{\circ} \mathrm{C}\right)(T)$ & 25.67 & 0.38 & 24.68 & 26.66 \\
\hline Total rainfall $(\mathrm{mm})(R)$ & 2319.7 & 563.8 & 1218.0 & 3873.3 \\
\hline Cropping intensity (\% area) $(\mathrm{Cl})$ & 170.3 & 22.9 & 125.0 & 222.0 \\
\hline $\begin{array}{l}\text { Area under groundwater } \\
\text { irrigation (\% area) (GW) }\end{array}$ & 17.26 & 18.80 & 0.00 & 73.00 \\
\hline $\begin{array}{l}\text { Area under surface water } \\
\text { irrigation (\% area) (SW) }\end{array}$ & 7.36 & 6.11 & 0.24 & 29.22 \\
\hline
\end{tabular}

deeper understanding of how regional variations in climate and management practices influence rice production, the present study developed linear mixed model. For the models, we lumped the three categories 'power pump/low lift pump', 'canals' and 'other' to represent surface water irrigation. All types of tube wells represent groundwater irrigation. We used percentage area per district of these two broad irrigation categories for the statistical analysis.

In the mixed model, rice yield $(\mathrm{Y})$ was used as the dependent variable (Eq. 1) where $i$ denotes different years (e.g. 1981-2010), $j$ identifies the 23 greater districts, $\beta$ and $a$ represent the fixed and random effects regression coefficients, respectively, and $\varepsilon_{i j}$ is the error term in the model. The independent variables in the model are average temperature $(T)$, total rainfall $(R)$, cropping intensity $(\mathrm{CI})$, area as a percentage of district area under surface water irrigation $(\mathrm{SW})$, area as a percentage of district area under groundwater irrigation $(\mathrm{GW})$, and year. The greater districts are represented as binary dummy variables $D_{2}$ to $D_{k}$.

$$
\begin{aligned}
Y_{i j}= & \beta_{0}+\beta_{1}\left(T_{i j}\right)+\beta_{2} \operatorname{sqrt}\left(R_{i j}\right) \\
& +\beta_{3} \log \left(\mathrm{CI}_{i j}\right)+\beta_{4} \log \left(\mathrm{GW}_{i j}\right)+\beta_{5} \log \left(\mathrm{SW}_{i j}\right) \\
& +\beta_{6}\left(\operatorname{year}_{i j}\right)+a_{2}\left(D_{i 2}\right)+\ldots+a_{j}\left(D_{i k}\right)+\varepsilon_{i j}
\end{aligned}
$$

Prior to model development, we tested the distribution of both dependent and independent variables using the ladder approach [38] and applied the most appropriate transformations (square root for $R$, and log transformation for $\mathrm{CI}, \mathrm{GW}$ and $\mathrm{SW}$ ). The transformed variables were assessed for co-linearity using the variance inflation factor (VIF) test in the $R$ statistical package. None of the variables showed a VIF value above 5 .

We also developed simple diagnostic linear models to assess the proportion of variance in yield that can be explained by different groups of determinants: climate ( $T$, $R$ ) and management (CI, GW, SW). In addition, we tested the level of geographic variation that can be explained by districts (D).

In order to assess how much the change in rice yield was affected by the different determinants during the study period, we estimated rice yield change $(\Delta y)$ relative to the change in the observations of independent variables $\left(\Delta x_{i}\right)$ in the models. In order to standardize the magnitude of the variability of the predictor variables, we used one standard deviation for each predictor variable $s\left(x_{i}\right)$ (Eq. 2; see Table 1 for standard deviation of the independent variables). The standardized relative effect is then the product of the model coefficient $\beta_{i}$ for any determinant multiplied by the standard deviation (transformed if appropriate) of $x_{i}$.

$$
\Delta y=s\left(x_{i}\right) \Delta \beta_{i}
$$




\section{Results}

\section{Spatial and temporal variation in rice yield, cropping intensity and irrigation types}

Rice yield in Bangladesh gradually increased during the study period from $1.4 \mathrm{t} /$ ha around 1980 to $2.7 \mathrm{t} /$ ha in 2010 (Fig. 2). Cropping intensity also increased initially but remained relatively constant between 1990 and 2005 (Fig. 2).

Total annual average rice yield, as averaged over the entire time period 1981-2010, shows high spatial variation across Bangladesh (Fig. 3a). The highest yield was observed in western districts including Rajshahi, Bogra and Jessore and the two hilly regions Chittagong and

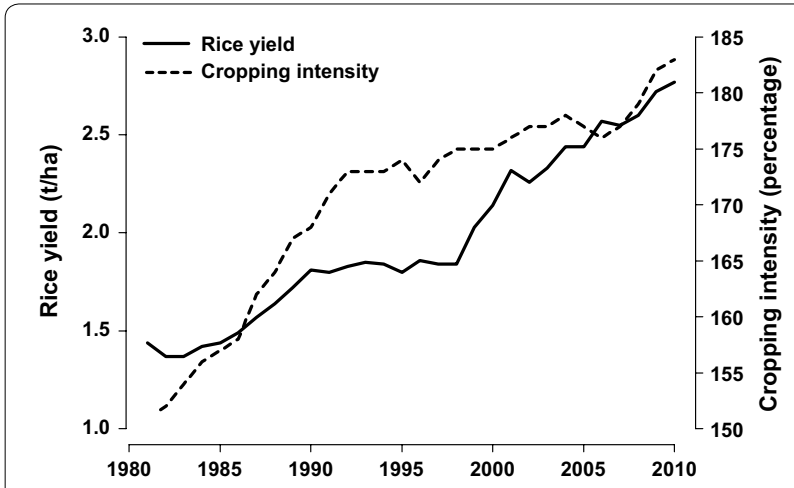

Fig. 2 Temporal trends in rice yield and cropping intensity in Bangladesh over the periods of 1981-2010
Khagrachari. These areas produced more than $2.12 \mathrm{t} /$ ha rice on average over the period. Some eastern districts, the centre of the country and one of the southern districts (Khulna) had low to medium yields with 1.572.12 t/ha. Only Patuakhali and Faridpur districts had very low average rice yields of less than $1.57 \mathrm{t} / \mathrm{ha}$.

Cropping intensity (average of 1981-2010) showed a different pattern (Fig. 3b). It was highest in some of the northern districts including Comilla and low to very low in hilly regions (Rangamati, Bandarban, and Khagrachari), forested areas (Khulna) and coastal districts of Bangladesh. Other districts, mostly covering the centre of the country, had medium to high cropping intensities (Fig. 3b).

Bangladesh experienced considerable changes in water management for irrigation during the study period with a substantial increase in the area equipped with motorized irrigation through tube wells (Fig. 4). This was largely due to the dramatic increase in percentage of the land area irrigated by tube wells in Bangladesh, which increased from 1.73 to 27.65 (Fig. 4). The area covered by power pumps/low lift pumps showed a slight increase, whilst the area under canals remained constant over the time period. The percentage of area under 'other' means of irrigation gradually decreased as old indigenous water lifting methods were replaced by modern irrigation technologies.
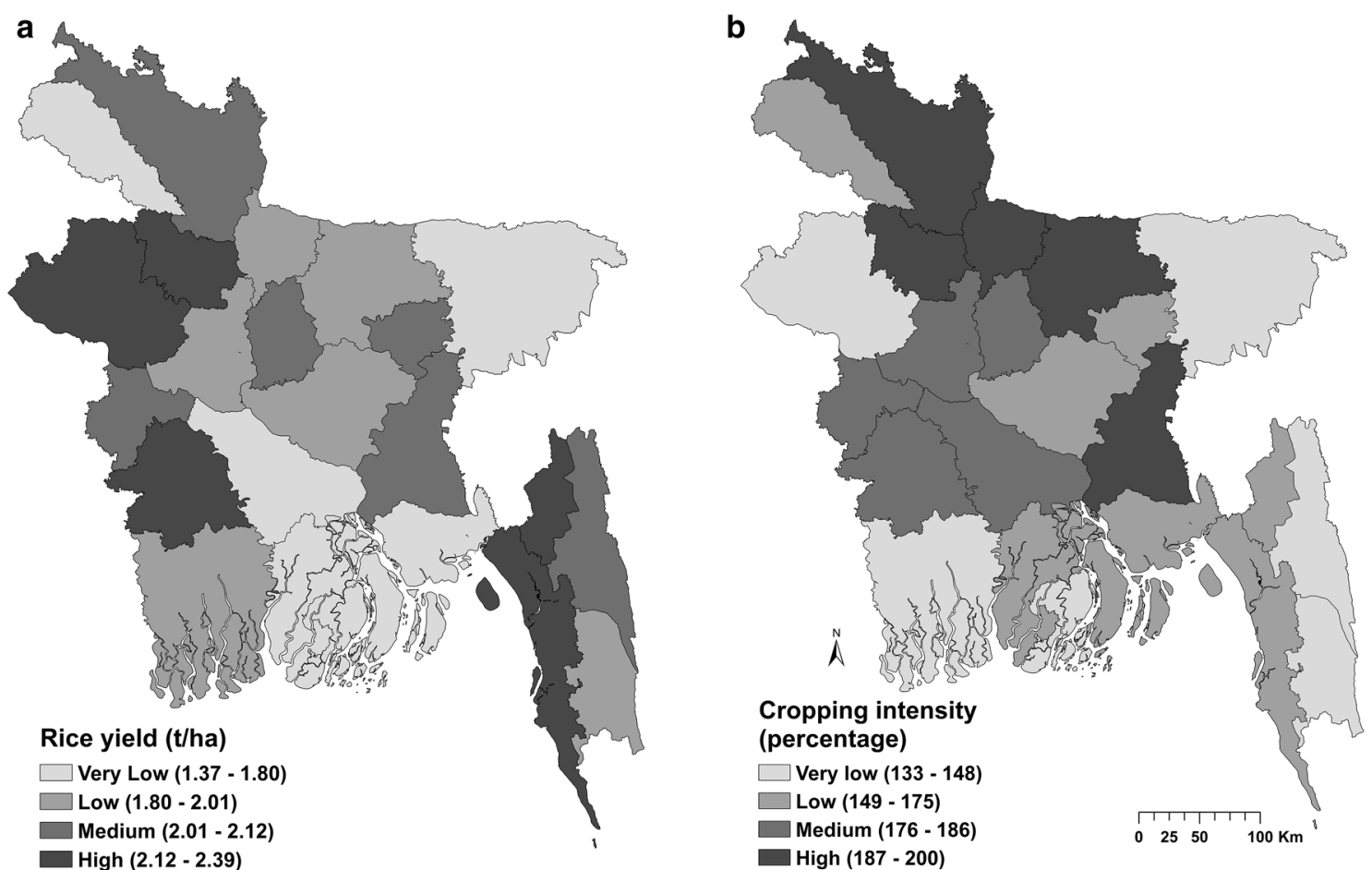

Fig. 3 Rice yield (a) and cropping intensity (b) in Bangladesh averaged over the 1981-2010 period; classes represent quartiles 


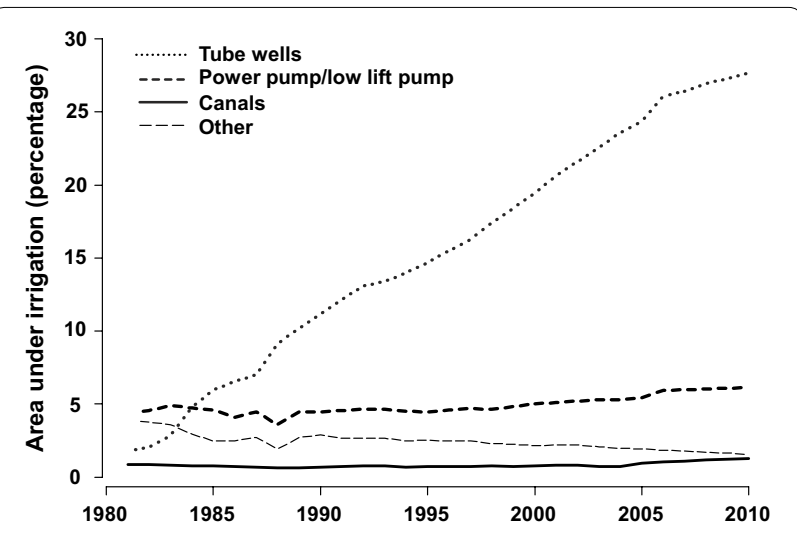

Fig. 4 Temporal trends in different means of irrigation as a percentage of area under irrigation relative to the total land area of Bangladesh, 1981-2010

Water management through different types of irrigation also varied regionally in Bangladesh in the study period. Most of the eastern and middle parts of the country were found to have high to very high proportions of area under power pump/low lift pump irrigation, except for three hilly districts (Rangamati, Bandarban and Khagrachari) (Fig. 5a). Other districts including the coastal areas had low to very low areas under power pump/low lift pump irrigation. Most of the northern and western districts have medium to high percentages of land under tube wells irrigation (Fig. 5b). A different geographic pattern can be observed for surface water irrigation through canals: it was very low to low in most of the northern, north-west and central districts of the country (Fig. 5c). Kustia, Jessore and Chittagong districts were observed to be high for this category. Areas under other traditional forms of irrigation were generally low for the entire country except for Sylhet, Kishoreganj, Comilla, Rangpur and Rajshahi districts (Fig. 5d).

\section{Relative importance of rice yield determinants}

The results of the mixed model are shown in Table 2 . Rice yield is negatively impacted by the climatic variables temperature and rainfall. Cropping intensity also has a significant negative effect. The contribution of water management through different types of irrigation to rice yields is prominent. Area under both groundwater and surface water irrigation exhibit strong positive effects in the model.

The effect plots for rice yield show the model response to the determinants and illustrate the response and variability of rice yield in the model (Fig. 6). Temperature and rainfall have a negative effect on rice yield, but the large error bands indicate a high level of uncertainty in the model. Increasing cropping intensity reduces yield in the model. Irrigation through groundwater has the strongest positive influence with the largest effect at low rates of the area under this category. Increased area of surface water irrigation also impacts positively on rice yield.

In addition to the mixed model, we also used simple linear models to assess the variability that can be explained by different groups of determinants (Table 3). The simplest model using only climatic variables explains $62 \%$ of the variation in rice yield. Using only management, the $R^{2}$ of the linear model is $66 \%$. Combining climatic and management determinants produces a model that can explain $67 \%$ of the rice yield variation. A further $22 \%$ of the variation can be explained including different districts, suggesting a remarkable impact of districts on yield through regional conditions. The model comparison (Table 3) shows a substantial reduction of AIC (Akaike Information Criterion) values with increasing model complexity. This demonstrates that the improvement in $R^{2}$ is not simply due to an increase in the number of model variables but that 'management' and particularly 'districts' are important determinants of rice yield.

The relative influence of the determinants of yield in the model can be effectively visualized by showing the changes in the modelled rice yield that arise from changes in the predictor variables, as shown in Fig. 7. Average temperatures show a small negative impact on rice yield, with a $0.05 \mathrm{t} / \mathrm{ha}$ decrease in rice yield observed for a temperature change of $0.38{ }^{\circ} \mathrm{C}$. Rainfall produces a very small reduction of $0.03 \mathrm{t} / \mathrm{ha}$ in yield. Also, increasing cropping intensity corresponds to a slightly reduced rice yield. Increasing the area under groundwater irrigation shows the strongest effect of an increase of yield $0.17 \mathrm{t}$ / ha, and increasing the area under surface water irrigation was also beneficial, contributing to a small increase of $0.03 \mathrm{t} /$ ha rice yield.

\section{Discussion}

The present study has analysed the factors that have influenced the spatial and temporal variation in rice yield in Bangladesh from 1981 to 2010. The results show substantial changes in space and time that can be correlated with climate variables, cropping intensity and water management practices through groundwater and surface water irrigation. Our analysis shows that management of water resources under groundwater irrigation had the strongest positive effect on rice yield during the study period. Climate variables and increased cropping intensity show a negative relationship.

\section{Irrigation}

Overall, the results demonstrate that water management affected rice yield very strongly in Bangladesh during the study period. Increased area under groundwater irrigation is most influential in our models. The area 

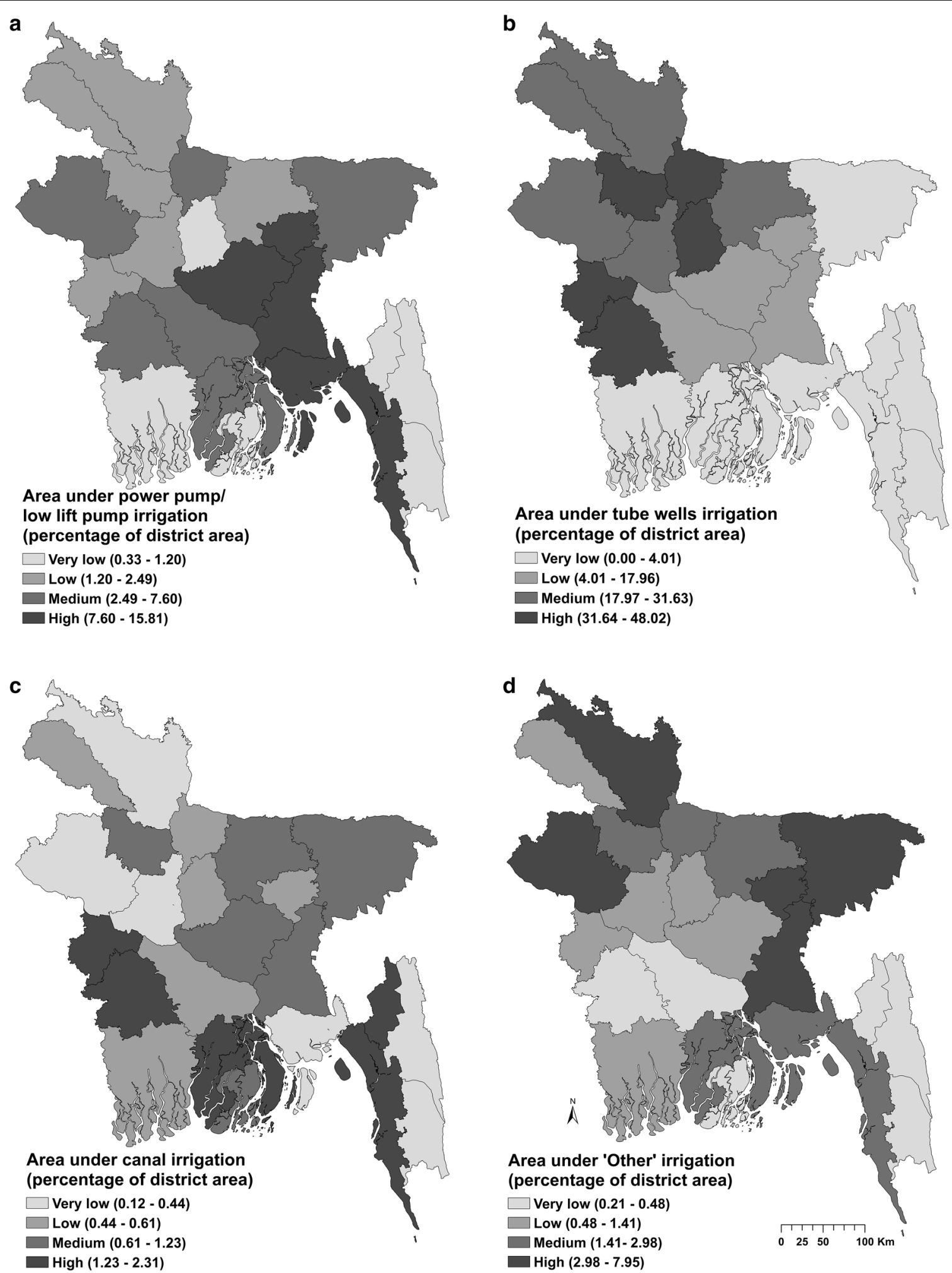

Fig. 5 Percentage of district area under different types of irrigation in Bangladesh: power pump/low lift pump (a), tube wells (b), canal irrigation (c) and other (d), averaged over the 1981-2010 period; classes represent quartiles 
Table 2 Coefficients of the linear mixed model predicting rice yields from climatic and management variable

\begin{tabular}{lcll}
\hline Determinants & Estimate & $\begin{array}{l}\text { Standard } \\
\text { error }\end{array}$ & $\boldsymbol{p}$ value \\
\hline Intercept & -68.380 & 2.631 & 0.000 \\
Temperature & -0.134 & 0.031 & 0.000 \\
Rainfall & -0.005 & 0.002 & 0.012 \\
$\begin{array}{l}\text { Cropping intensity } \\
\text { Area under groundwater }\end{array}$ & -0.989 & 0.149 & 0.000 \\
$\quad$ irrigation & 0.584 & 0.036 & 0.000 \\
Area under surface water & 0.223 & 0.069 & 0.001 \\
$\quad$ irrigation & & & 0.000 \\
\hline
\end{tabular}

under surface water irrigation also positively influences rice yield, but the effect is smaller because of a limited increase in the area of this category during the study period. Further, the present study illustrates that means of irrigation varied regionally (Fig. 5). Tube well irrigation had the highest area (up to $48 \%$, Fig. 5b) with distinct geographic differences because groundwater is more
Table 3 Comparison of separate models predicting yield using different indicator categories

\begin{tabular}{llll}
\hline Models & Adjusted $\boldsymbol{R}^{\mathbf{2}}$ & $\boldsymbol{p}$ values & \multicolumn{1}{l}{ AIC } \\
\hline Climate & 0.62 & 0.000 & 407.16 \\
Management & 0.66 & 0.000 & 317.55 \\
Climate + management & 0.67 & 0.000 & 307.46 \\
Climate + management + districts & 0.89 & 0.000 & -453.70 \\
\hline
\end{tabular}

accessible in north-western districts [39, 40]. In contrast, southern districts are more susceptible to salinity intrusion than any other parts of the country $[41,42]$, resulting in a lower use of tube wells (Fig. 5b).

\section{Climatic variables}

Yield shows a negative correlation with temperature and rainfall during the study period. This corresponds with findings from simulation models, which indicated a decreased rice yield under temperature increase in future scenarios of climate change [17-21]. The temperature effect in the model is not strong, with a slope in
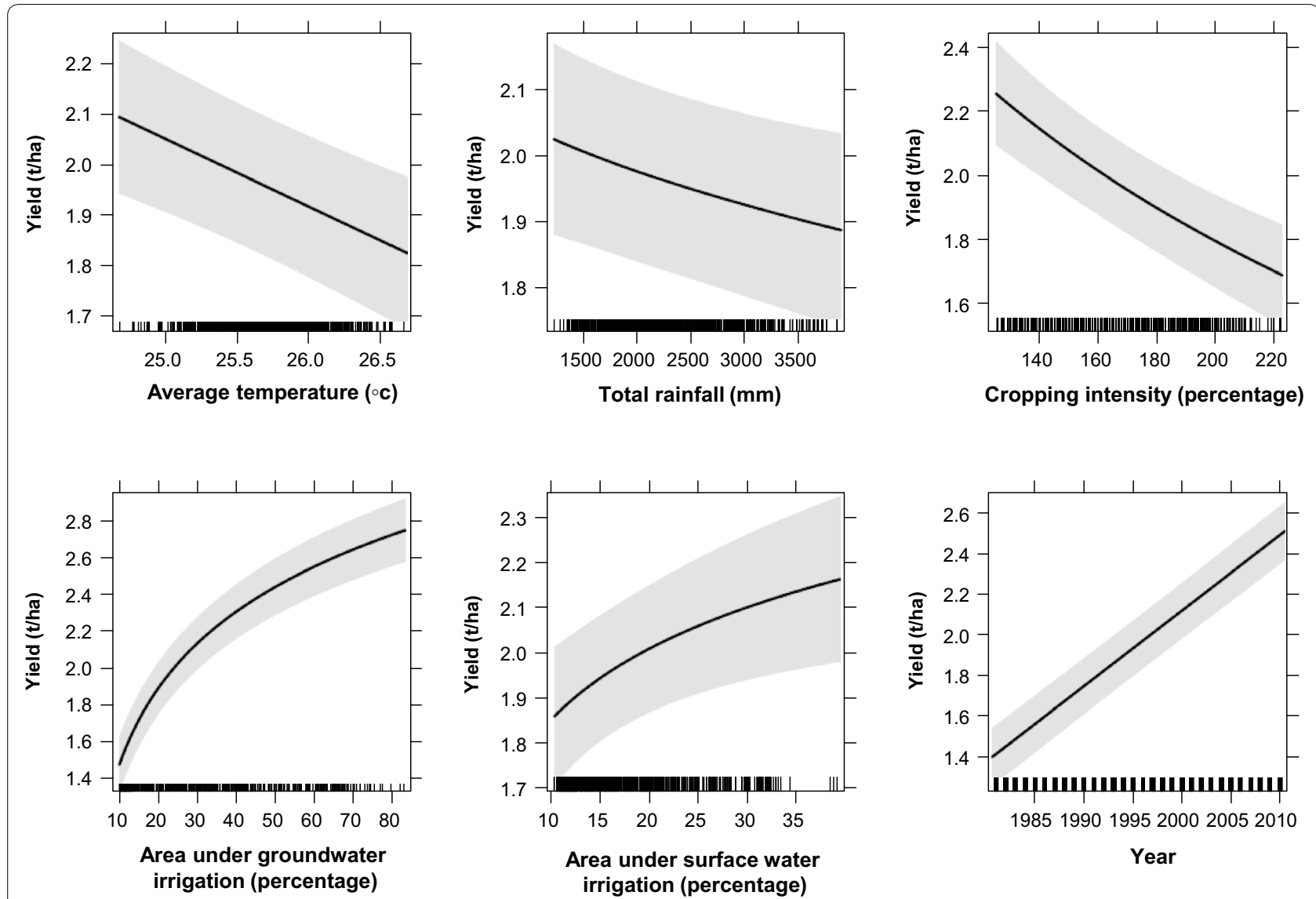

Fig. 6 Effect plots for rice yield determinants in Bangladesh (1981-2010). The shaded bands show 0.95 confidence limits for the effects 


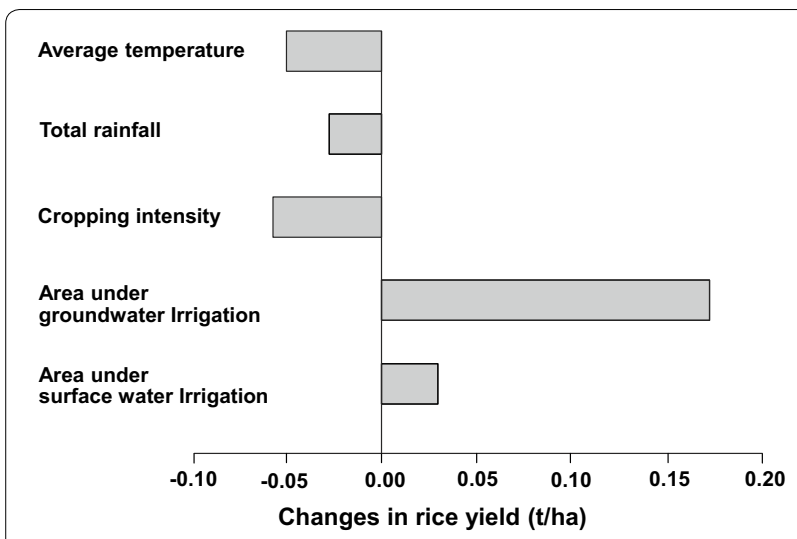

Fig. 7 Relative effect of rice yield determinants. This figure shows the changes in the modelled rice yield (t/ha) that arises from standardized changes in the predictor variables

the model of approximately $0.14 \mathrm{t} / \mathrm{ha}$ rice yield per $1{ }^{\circ} \mathrm{C}$. The effect of rainfall on yield is also negative. Whereas the intensity of disasters, especially drought, and flooding may affect rice yield regionally $[19,43]$, data were not available at the spatial and temporal resolution and extent of the present study. Hence, our results need to be treated with some level of caution. There is also a strong unexplained temporal trend in yield as indicated by the significant effect of time in the model. Temperature has increased during the study period, and this could potentially cause spurious effects in the model.

\section{Cropping intensity}

Cropping intensity increased substantially during the study period from $151 \%$ in 1981 to $183 \%$ in 2010 with relatively stable conditions during 1990-2005. Cropping intensity had a small but significantly negative effect on yield during the study period. This may initially seem counter-intuitive, as clearly the increase in cropping intensity was a major contributor to food security nationally [28]. Whilst we find that cropping intensity has a negative effect on yield in the models, this does not contradict the fact that production is positively influenced by cropping intensity because cropping intensity implies an increase in the number of harvests. Also, cropping intensity and yield are positively correlated in one-dimensional models, but once irrigation is included as covariate in multivariate models based on our dataset, the correlation between cropping intensity and yield changes. Our results show that the effect of irrigation on yield outweighs the effects of cropping intensity and, in fact, turns it slightly negative. A possible explanation may be that in those districts with a low cropping intensity, where production depends on one or two crops per year, farmers may consider a more intensive cultivation. However, there are small data to underpin this possibility and the effect in the models is small.

\section{Modelling issues and data limitation}

The results also indicated that the empirical models developed in this study are underspecified since we were not able to include several variables that are known to influence regional rice yield because information is unavailable. A large amount of additional variance was explained by simply adding districts as an independent variable to the model. This indicates that there are strong regional differences in rice yield, which cannot be quantified due to lack of spatio-temporal data on these variables. Likely candidates for these variables are biophysical environmental conditions such as soils and management factors that relate to intensification. Potentially important is the use of fertilizer and pesticides, ploughing practices, the quality of seeds, or the record of adoption of highyielding rice varieties in different areas in Bangladesh. This lack of additional spatio-temporal information is likely the most critical weakness in our models.

\section{Conclusion}

The present study has analysed the combined impact of climate and management practices on rice yield in Bangladesh. Area under irrigation had a far stronger effect on rice yield in Bangladesh than climatic variables and cropping intensity during the study period.

Our study indicates that in particular groundwaterdependent irrigation through tube wells appears to be the dominating factor for rice yield differences in space and time. The result is alarming because it indicates that the recent production level is only sustainable if the area under groundwater irrigation can be maintained. Therefore, it is crucial to continue to utilize groundwater for irrigation. However, there is already evidence of overexploitation of groundwater in some areas and there are concerns that the current pumping rates may not be sustainable [28]. Further increasing of area under groundwater irrigation is a challenging task, and some areas may even need a reduction in groundwater irrigation because aquifers are overused. In contrast, surface water irrigation was relatively constant during the study period. Both groundwater and surface water salinity are a major concern for irrigation development in coastal areas, limiting further expansion of land under irrigation in these areas that make up $30 \%$ of the total cultivable land [36] of Bangladesh. In addition, groundwater extraction through tube wells increases the risk of arsenic contamination in many parts of the country and industrial pollution may deteriorate surface water quality for irrigation [36]. Worse, production needs to be increased to compensate 
future population growth in Bangladesh [26]. Therefore, policies need to incorporate water management options critically in different districts by combining groundwater with the use of other water sources for irrigation. This puts substantial pressure on policy development because of the need to consider conflicting interest on the use of water resources, supporting more efficient and sustainable use of water and environmental stewardship [36] to ensure future food security.

Although the effect of climatic variables was much smaller than that of water management variables, it is an important consideration for the future sustainability of rice production in Bangladesh. Whilst future weather conditions cannot be controlled, adaptation to changes in climate may be possible through different varieties or space-specific changes in management practices (i.e. irrigation, fertilization, timing) in order to compensate for the negative effects on food security in a long run $[15$, $16,33]$. Climate change effects such as extreme events (flooding, drought), not considered in the present study, may also influence rice production in different areas. However, climate change may impact seasonal climatic conditions, affecting the rice eco-types differently [22] highlighting the need to assess rice eco-types specific impacts explicitly in future studies.

The importance of region-specific effects (only crudely incorporated as districts in the present study) may also be seen as evidence that regional conditions should be considered importantly in food policy. Our results indicate that the best management practices and adaptation measures will likely vary spatially, requiring regionspecific policies in order to sustain the country's food security. Specific regional differences due to biophysical, infrastructure and management variables may also impact rice cultivation regionally, but could not be included into our study. Furthermore, cultivable area of the country is declining at a rate of $1 \%$ per year [26], further increasing pressures from different conflicting potential land uses.

The study underpins the important role that water management has played in food security for Bangladesh, and it indicates that there is scope for improvement in rice yield by understanding the region-specific limitations and how they can be overcome.

\footnotetext{
Abbreviations

AIC: Akaike Information Criterion; BBS: Bangladesh Bureau of Statistics; BCCSAP: Bangladesh Climate Change Strategy and Action Plan; BMD: Bangladesh Meteorological Department; CERES: Crop Environment Resource Synthesis; DSSAT: Decision Support System for Agro-technology Transfer; FAO: Food and Agriculture Organization; GIS: Geographic Information System; IRRI: International Rice Research Institute; MoEF: Ministry of Environment and Forest; MoFDM: Ministry of Food and Disaster Management; NAPA: National Adaptation Programme of Action; VIF: Variance Inflation Factor.
}

\section{Authors' contributions}

IA conceived the study idea, collected data, performed analysis, interpreted the data and wrote the manuscript. ML revised it critically for important intellectual content. BO contributed to the analysis and provided a critical evaluation of the manuscript. All authors read and approved the final manuscript.

\section{Author details}

${ }^{1}$ School of Biological Sciences, The University of Adelaide, Adelaide 5005, Australia. ${ }^{2}$ Department of Geography and Environment, Jahangirnagar University, Savar, Dhaka 1342, Bangladesh.

\section{Acknowledgements}

This research is funded by the Australian Government and University of Adelaide through an International Postgraduate Research Scholarship (IPRS) and Australian Postgraduate Award (APA) for the first author to pursue her Ph.D. The lead author is particularly thankful to Dr. Margaret Cargill, a research communication specialist at the University of Adelaide, for review of this manuscript. Special acknowledgment goes to the Bangladesh Meteorological Department (BMD) for providing climate data.

\section{Competing interests}

The authors declare that they have no competing interests. They have, of course, personal and professional interests in the success of such innovations on climate change and natural resource management for Bangladesh food security policy implications.

Received: 4 February 2016 Accepted: 5 July 2016

Published online: 19 July 2016

\section{References}

1. Ostendorf B. Overview: spatial information and indicators for sustainable management of natural resources. Ecol Ind. 2011;111:97-102. doi:10.1016/j.ecolind.2010.10.003.

2. Nasrin S, Bergman Lodin J, Jirström M, Holmquist B, Andersson Djurfeldt A, Djurfeldt G. Drivers of rice production: evidence from five SubSaharan African countries. Agric Food Secur. 2015;41:1-19. doi:10.1186/ s40066-015-0032-6.

3. lizumi T, Ramankutty N. How do weather and climate influence cropping area and intensity? Glob Food Secur. 2015;4:46-50. doi:10.1016/j. gfs.2014.11.003

4. Omoyo NN, Wakhungu J, Oteng'i S. Effects of climate variability on maize yield in the arid and semi arid lands of lower eastern Kenya. Agric Food Secur. 2015;41:1-13. doi:10.1186/s40066-015-0028-2.

5. Qin Y, Liu J, Shi W, Tao F, Yan H. Spatial-temporal changes of cropland and climate potential productivity in northern China during 1990-2010. Food Secur. 2013:54:499-512. doi:10.1007/s12571-013-0280-x.

6. Smilovic M, Gleeson T, Siebert S. The limits of increasing food production with irrigation in India. Food Secur. 2015;74:835-56. doi:10.1007/ s12571-015-0477-2.

7. Diagne M, Demont M, Seck P, Diaw A. Self-sufficiency policy and irrigated rice productivity in the Senegal River Valley. Food Secur. 2013;51:55-68. doi:10.1007/s12571-012-0229-5.

8. Tong C, Hall CAS, Wang H. Land use change in rice, wheat and maize production in China (1961-1998). Agric Ecosyst Environ. 2003;952-3:523-36. doi:10.1016/S0167-8809(02)00182-2.

9. Kumar MD, Sivamohan MVK, Narayanamoorthy A. The food security challenge of the food-land-water nexus in India. Food Secur. 2012;44:539_ 56. doi:10.1007/s12571-012-0204-1.

10. Deryng D, Sacks W, Barford C, Ramankutty N. Simulating the effects of climate and agricultural management practices on global crop yield. Glob Biogeochem Cycles. 2011;25:1-18. doi:10.1029/2009GB003765.

11. FAO. Looking ahead in world food and agriculture: perspective to 2050. Rome, Italy; 2011.

12. IRRI. International Rice Research Institute. 2015. irri.org/our-impact/ increase-food-security. Accessed 23 Dec 2015.

13. BBS. Household income and expenditure survey. Dhaka: GoB; 2005

14. BBS. Agricultural statistical year book of Bangladesh. Dhaka: GoB; 2010. 
15. MoEF. National Adaptation Programme of Action (NAPA). Dhaka: Ministry of Environment and Forest, GoB; 2005.

16. MoEF. Bangladesh Climate Change Strategy and Action Plan (BCCSAP). Dhaka: Ministry of Environment and Forest GoB; 2009.

17. Karim Z, Hussain S, Ahmed M. Assessing impacts of climatic variations on foodgrain production in Bangladesh. Water Air Soil Pollut. 1996;921:53-62.

18. Basak JK, Ali MA, Islam MN, Rashid MA. Assessment of the effect of climate change on boro rice production in Bangladesh using DSSAT model. Journal of Civil Engineering. 2010;382:95-108.

19. Ruane AC, Major DC, Yu WH, Alam M, Hussain SG, Khan AS, et al. Multifactor impact analysis of agricultural production in Bangladesh with climate change. Glob Environ Change. 2013;231:338-50. doi:10.1016/j. gloenvcha.2012.09.001.

20. Rimi RH, Rahman SH, Karmakar S, Hussain SG. Trend analysis of climate change and investigation on its probable impacts on rice production at Sathkhira, Bangladesh. Pak J Meteorol. 2009;6:37-50.

21. Basak JK, Alam K. Impacts of carbon dioxide emission and subsequent rise of temperature on rice production in Bangladesh: implications for food security. Int Res J Environ Sci. 2013;2:60-7.

22. Md Abdur Rashid S, Alam K, Gow J. Exploring the relationship between climate change and rice yield in Bangladesh: an analysis of time series data. Agric Syst. 2012;1120:11-6. doi:10.1016/j.agsy.2012.06.004.

23. Md. Abdur Rashid S, Khorshed A, Jeff GA. Comparison of the effects of climate change on Aus, Aman and Boro rice yields in Bangladesh: evidence from panel data. Paper presented at the 41 st Australian conference of economists, Melbourne. 2012, July 8-11.

24. Rahman S. Six decades of agricultural land use change in Bangladesh: effects on crop diversity, productivity, food availability and the environment, 1948-2006. Singap J Trop Geogr. 2010;312:254-69. doi:10.1111/j.1467-9493.2010.00394.x.

25. Alauddin M, Sharma BR. Inter-district rice water productivity differences in Bangladesh: an empirical exploration and implications. Ecol Econ. 2013;930:210-8. doi:10.1016/j.ecolecon.2013.05.015.

26. Mainuddin M, Kirby M. National food security in Bangladesh to 2050. Food Secur. 2015;73:633-46. doi:10.1007/s12571-015-0465-6.

27. Mainuddin M, Kirby M, Chowdhury R, Shah-Newaz S. Spatial and temporal variations of, and the impact of climate change on, the dry season crop irrigation requirements in Bangladesh. Irrig Sci. 2015;332:107-20. doi:10.1007/s00271-014-0451-3.

28. Ahmad MU, Kirby M, Islam M, Hossain MJ, Islam MM. Groundwater use for irrigation and its productivity: status and opportunities for crop intensification for food security in Bangladesh. Water Resour Manag. 2014;285:1415-29. doi:10.1007/s11269-014-0560-z.

29. Statistical Yearbook of Bangladesh. Dhaka, Bangladesh: GoB; 2012. http:///BBS 2012.

30. Shah T, Sing OP, Mukherji A. Some aspect of South Asia's groundwater irrigation economy: analyses from a survey in India, Pakistan, Nepal Terai and Bangladesh. Hydrogeol J. 2006;14:286-309. doi:10.1007/ s10040-005-0004-1.

31. Parvin $L$, Rahman MW. Impact of irrigation on food security in Bangladesh for the past three decades. J Water Resour Protect. 2009;3:216-25. doi:10.4236/jwarp.2009.13027.

32. BBS. Agricultural statistical yearbook of Bangladesh. Dhaka: GoB; 2012.

33. MoFDM. National Food Policy (NFP). Dhaka: Ministry of Food and Disaster Management, GoB; 2006.

34. MoFDM. National Food Policy Plan of Action (NFPPA). Dhaka: Bangladesh Food Planning and Monitoring Unit (FPMU), Ministry of Food and Disaster Management, GoB; 2008.

35. BBS. Agricultural statistical year book of Bangladesh. Dhaka: GoB; 2012.

36. Rahman R, Mondal MS. Role of water resource management in ensuring food security. In Habiba U, Abedin MA, Hassan AWR, Shaw R, editors. Food security and risk reduction in Bangladesh. Japan: Springer; 2015. p. 213-234. doi:10.1007/978-4-431-55411-0_12.

37. BMD. Climate database. Dhaka: Bangladesh Meteorological Department; 2012.

38. Tukey JW. Exploratory data analysis. Reading: Addition-Wesley; 1977.

39. Jahani CS, Ahmed M. Flow of groundwater in the Barind area, Bangladesh: implication of structural framework. J Geol Soc India. 1997;506:743-52.

40. Rahman MM, Mahbub A. Groundwater depletion with expansion of irrigation in Barind Tract: a case study of Tanore Upazila. J Water Resour Protect. 2012;408:567. doi:10.4236/jwarp.2012.48066.

41. Habibullah M, Ahamad AU, Karim Z. Assessment on Food Grain Production Loss Due to Climate Induced Enhanced Soil Salinity. In: Huq S, Karim Z, Asaduzzaman M, Mahtab F, editors. Vulnerability and adaptation to climate change for Bangladesh. Dordrecht: Kluwer; 1998. p. 55-70.

42. Mondal MK, Bhuiyan SI, Franco DT. Soil salinity reduction and prediction of salt dynamics in the coastal ricelands of Bangladesh. Agric Water Manag. 2001;471:9-23. doi:10.1016/s0378-3774(00)00098-6.

43. Shahid S. Spatial and temporal characteristics of droughts in the western part of Bangladesh. Hydrol Process. 2008;2213:2235-47. doi:10.1002/ hyp.6820.

\section{Submit your next manuscript to BioMed Central and we will help you at every step:}

- We accept pre-submission inquiries

- Our selector tool helps you to find the most relevant journal

- We provide round the clock customer support

- Convenient online submission

- Thorough peer review

- Inclusion in PubMed and all major indexing services

- Maximum visibility for your research

Submit your manuscript at www.biomedcentral.com/submit
BioMed Central 